\title{
Medical Students' Response to: Willingness and Self-Perceived Competence of Final-Year Medical Students to Work as Part of the Healthcare Workforce During the COVID-I9 Pandemic [Letter]
}

\section{Ahmad Almohtadi (D) Golnoush Seyedzenouzi}

St George's University of London, London, Tooting SWI7 ORE, UK
Correspondence: Ahmad Almohtad St George's University of London, Cranmer Terrace, London, Tooting SWI7 ORE, UK

EmailmI500088@sgul.ac.uk
This article was published in the following Dove Press journal: International Journal of General Medicine

\section{Dear editor}

We read with great interest the article published by AlSaif et al ${ }^{1}$ investigating the relationship between the willingness of final-year medical students to participate in the response towards COVID-19, and their perceived clinical competence. The pandemic has resulted in significant staff shortages requiring the help of volunteers to compensate for professionals lost to the outbreak. ${ }^{2}$ Therefore, this article comes at a critical time to allow for a better understanding of the influences that would impact final-year medical students' willingness to contribute to the response.

Although the authors have attempted to correlate perceived clinical competence and willingness to volunteer during the pandemic, the questionnaire used address general competencies, rather than ones that are relevant to the COVID-19 response. These general competencies encompass a wide array of skills that are not necessarily needed, or expected, from a volunteering student. For example, the authors ask about the perceived competence in "essential clinical procedures" which can vary from complex intubation to simple venepuncture. As medical students, we would expect the questionnaire to include specific tasks required, eg performing nasopharyngeal swabs, to successfully judge our competence. The questionnaire also includes skills that are unlikely to be needed, such as "select and apply the most appropriate and cost-effective diagnostic procedures" which would generally be expected from senior doctors rather than the students. The general nature of the questions has therefore likely influenced the results of the study, providing an inaccurate reflection about the true willingness of students to help during large-scale outbreaks.

Various studies such as that of Miller et $\mathrm{al}^{3}$ demonstrate that volunteering students were asked to perform simpler tasks, and often non-COVID-19 related, such as routine outpatient clinical care, hosting PPE drives and calling patients with lab results. These tasks although play a critical role in patients' outcomes and ease the stress of healthcare systems, they do not require extensive expertise, nor do they pose a high risk of COVID-19 transmission. Therefore, it would be more appropriate for the questionnaires to include such tasks when assessing for willingness. 
A similar study by Tempski et $\mathrm{al}^{4}$ utilized specific and relevant competencies to assess for willingness to volunteer, such as "I feel able to communicate the diagnosis for COVID-19 infection" and "I know how to use personal protection equipment (PFE)", providing relevant and valuable results.

Furthermore, the study overlooked an important social aspect: students living with high-risk individuals, such as senior family members with co-morbidities. ${ }^{5}$ Students may be clinically competent but are reluctant, ie not willing, to volunteer to protect the wellbeing of these individuals. This creates a subconscious dilemma between choosing one's moral duties and prioritising family needs. This would have also impacted the results of this study, and therefore should have been included.

We congratulate the authors for this comprehensive study but suggest a more detailed and specific methodology for future assessments. We believe this would provide an invaluable insight into the attitudes of medical students that would help healthcare systems better understand how to integrate medical students in future crises.

\section{Disclosure}

The authors report no conflicts of interest for this communication.

\section{References}

1. AlSaif HI, AlDhayan AZ, Alosaimi MM, et al. Willingness and Self-Perceived Competence of Final-Year Medical Students to Work as Part of the Healthcare Workforce During the COVID-19 Pandemic. Int J Gen Med. 2020;13:653-661. doi:10.2147/IJGM.S272316

2. Rasmussen S, Sperling P, Poulsen MS, Emmersen J, Andersen S. Medical students for health-care staff shortages during the COVID-19 pandemic. Lancet. 2020;395(10234):e79-e80. doi:10. 1016/S0140-6736(20)30923-5

3. Miller DG, Pierson L, Doernberg S. The Role of Medical Students During the COVID-19 Pandemic. Ann Intern Med. 2020;173 (2):145-146. doi:10.7326/M20-1281

4. Tempski P, Arantes-Costa F, Kobayasi R, et al. Medical students perceptions and motivations in time of COVID-19 pandemic. medRxiv. 2020. doi:10.1101/2020.05.28.20115956

5. Dubey S, Biswas P, Ghosh R, et al. Psychosocial impact of COVID-19. Diabetes Metab Syndr. 2020;14(5):779-788. doi:10. 1016/j.dsx.2020.05.035

Dove Medical Press encourages responsible, free and frank academic debate. The content of the International Journal of General Medicine 'letters to the editor' section does not necessarily represent the views of Dove Medical Press, its officers, agents, employees, related entities or the International Journal of General Medicine editors. While all reasonable steps have been taken to confirm the content of each letter, Dove Medical Press accepts no liability in respect of the content of any letter, nor is it responsible for the content and accuracy of any letter to the editor.

\section{Publish your work in this journal}

The International Journal of General Medicine is an international, peer-reviewed open-access journal that focuses on general and internal medicine, pathogenesis, epidemiology, diagnosis, monitoring and treatment protocols. The journal is characterized by the rapid reporting of reviews, original research and clinical studies across all disease areas. The manuscript management system is completely online and includes a very quick and fair peer-review system, which is all easy to use. Visit http://www.dovepress.com/ testimonials.php to read real quotes from published authors. 